\title{
Nas mãos um fuzil, nos pés uma bola: uma releitura sobre 0 jovem da novela Inferno, de Patricia Melo
}

Daiana Santos*

\begin{abstract}
Resumo: O presente trabalho analisará a novela Resumen: El pretendido trabajo intentará, a partir de brasileira Inferno de Patrícia Melo. Será analisado o novela brasileña Inferno, de Patrícia Melo, analizar el cenário violento das grandes cidades brasileiras, escenario violento de las grandes ciudades brasileñas y principalmente, do Rio de Janeiro. Dessa maneira, principalmente de Río de Janeiro. De esta manera, tentaremos construir o perfil do jovem da favela, intentaremos construir el perfil del joven de la "favela", partindo do seu personagem principal, Reizinho. Ao desde su personaje principal, Reizinho. Al mismo mesmo tempo, trataremos do tema das expectativas tiempo, plantearemos el tema de las expectativas de desse jovem morador da favela e, sobretudo do poder este joven que vive en la "favela" y, antes que todo, del que a criminalidade exerce sobre os jovens pobres da poder que la criminalidad ejerce sobre los jóvenes sin atualidade. recursos de la actualidad.
\end{abstract}

Palavras-chave: favela, jovem, violencia, cidades

Palabras- clave: favela; joven; violencia; ciudades

\section{Introducíon}

A partir de los años 70, la violencia en Brasil empieza a presentarse paulatinamente en las grandes ciudades, llegando a alcanzar altos niveles en la actualidad, lo que produjo/produce un escenario de miedo, inseguridad y cambios profundos en la población, sobre todo en los jóvenes.

El presente trabajo intentará- a partir de la novela Inferno de la escritora brasileña Patricia Melo (2003) - analizar la violencia en la juventud brasileña de bajo poder adquisitivo presente en las grandes ciudades, a priori se plantearán estas perspectivas a partir de la referida obra que desarrolla muy bien tal temática.

\footnotetext{
* Graduada em Letras pela Universidade Estadual de Santa Cruz em Ilhéus na Bahia. Mestrado em LiteraturaUniversidad de Chile em Santiago,Chile. Area de Pesquisa: Literatura Brasileira santos.daiana@bol.com.br. Trabalhos relevantes na área: Palestra "Cultura baiana e Jorge Amado" no Centro de Estudos Brasileiros da Embaixada do Brasil no Chile. Comunicação "La hoz y el martillo en la escritura de Jorge Amado" nas VII Jornadas de Estudiantes de Postgrado de la Facultad de Humanidad de la Universidad de Chile.Comunicação "El caso del "willkommen" de Hans Staden entre los tupinambás en Brasil" na Conferencia Internacional La ciudad en lo imaginario em Valparaiso,Chile.
} 
La novela Inferno es el libro más denso y profundo de Patricia Melo, pues traza un escenario de personajes de Río de Janeiro y narra la historia de José Luis Reis, más conocido por Reizinho, un chico de 11 años, ex adicto al crack y que posteriormente se torna el jefe del tráfico en el 'Morro do Berimbau'.

Es necesario decir que el libro presenta la violencia en varias fases, disfraces e intensidades. Las situaciones de violencia presentadas en la novela se relacionan con los problemas sociales mostrados a lo largo de la narrativa y que se refieren- básicamente- al tráfico de drogas, a la desigualdad social presentes en el escenario brasileño.

Sin embargo, en el presente trabajo el cuestionamiento apunta a explicar cómo la violencia se hace presente en la vida del joven y cómo interfiere en su formación personal y adulta, produciendo un cambio de manera prematura de la infancia a la etapa adulta. Al mismo tiempo, será planteada la hipótesis de cómo los factores externos (sociales y familiares) son importantes para la construcción de este joven, inserto en un escenario de violencia.

El presente trabajo será dividido en tres partes: en la primera, se hablará del escenario violento que presentado en la novela Inferno y en las grandes ciudades brasileñas; en la segunda, se intentará construir el sujeto joven a partir del personaje Reizinho, hablando de los cambios que suceden en su vida y que afectan su proceso de formación y que por fin, lo convierte en el líder del tráfico; en la tercera parte, se hablará de cuáles son las expectativas de este joven involucrado en este escenario violento de Río de Janeiro y de las grandes metrópolis brasileñas.

\section{El escenario violento de las grandes ciudades brasileñas}

A partir de los años 70 del siglo pasado, Brasil se configuró efectivamente como una nación capitalista y moderna, aunque con un alto nivel de desigualdad social. Sin embargo, el buen crecimiento económico de la década de 70, proveniente de la propaganda de la dictadura militar, atrajo millones de trabajadores rurales para los grandes centros urbanos con esperanzas de una vida mejor. No obstante, algunos de estos se integraron a la vida urbana, pero otros, fueron a vivir en favelas $^{1}$ que fueron surgiendo en larga escala en las grandes metrópolis brasileñas. En las décadas de 1980 y 1990, las cifras de crecimiento económico bajaron significativamente, no permitiendo la integración de los sectores más pobres al desarrollo nacional.

\footnotetext{
${ }^{1}$ Conjunto de habitaciones populares, generalmente tosca, sin condiciones de higiene, construidas en morros cercanos a los grandes centros urbanos.
} 
En esta perspectiva, se generaron problemas sociales y de valores que produjeron inseguridad en los senos familiares brasileños, sustituyendo sus códigos patriarcales a nuevos comportamientos y expectativas correspondientes al medio urbano y capitalista. Así, nuevos códigos pasaron a formar parte de esta nueva generación de las grandes ciudades.

De esta manera, en la novela Inferno se presenta una sociedad inestable, violenta y en un caos profundo que se va revelando en la familia y en la sociedad. Para Muniz Ferreira (2004, p. 72), la familia está perdiendo su fuerza y función social en la sociedad actual, pues se están cambiando los valores tradicionales por otros códigos que contribuyen a la desestabilización familiar. Se puede percibir este fenómeno en la novela estudiada, pues los lazos familiares de la familia de Reizinho se deshacen a todo momento, ya que hay una inestabilidad en este relacionamiento, sobre todo en las relaciones frágiles que presentadas: la madre que lo agredía físicamente, la ausencia y el deseo de conocer a su padre además de la relación deficiente con su hermana y su abuela. En su caso, estos hechos fueron esenciales para que él se involucrase con la banda de droga de la favela en que vivía.

De esta manera, a lo largo de la novela se presenta la sociedad actual en las grandes metrópolis brasileñas y la enorme violencia emergente de los problemas sociales del pasado que se reflejan en la actualidad. Es necesario señalar que los actos violentos referidos en dicha novela, se reflejan en las necesidades sufridas por la población, en el abandono del Estado, la pérdida de la niñez, en el embarazo precoz y en el caso de Reizinho, en la lucha por su vida. Estos elementos están relacionados en un ambiente violentado por la mentira, traición, vicios, corrupción que a larga escala forma parte del escenario social vivido por los moradores de las favelas de Rio de Janeiro y de otras grandes ciudades brasileñas, que sufren con el avance de la violencia y el olvido de las autoridades que los consideran como sujetos sin importancia, proporcionando así el creciente poder de los traficantes y de las bandas de drogas para con estas personas que viven en las favelas. En el escenario de Inferno, el Estado no cumple con sus obligaciones: salud, escuela, seguridad, habitaciones; pues falla como institución, dejando a cargo de una manera indirecta, ciertas obligaciones para las bandas de drogas. Sin embargo, estos sujetos se aprovechan de esta ausencia del Estado y de esta carencia para dictar sus propias leyes e intenciones, actuando- según sus planes- en territorio que la policía no tiene espacio y el Estado no escucha la voz de los que ahí viven. Así, las bandas de drogas ganan la simpatía, el respeto y la fidelidad de los que ahí viven y que frecuentemente reciben su ayuda, esto es lo que muestra el fragmento abajo:

Quando entrevistados, os moradores apoiavam seus líderes. Estamos com o Zequinha, diziam. O Zequinha, para nós, é um homem de ouro, declarara uma entrevistada. Bom coração. Ele que 
paga os remédios do meu rim. Eu gosto do Miltão, afirma outra, porque ele faz tudo o que um prefeito deveria fazer. As críticas, quando apareceriam, não possuíam alvos. (MELO, 2003 p. 158)

De esta manera, lo que se ve es una total falencia de la policía y del Estado, pues ambos fallan como institución y se muestran incapaces de detener los hechos que suceden en las favelas brasileñas, poniendo a la población en constante miedo e inseguridad. Esta acción se puede ver en la afirmación de la narradora:

O Brasil conhecia todos os detalhes das batalhas sangrentas por meio de artigos como aqueles e das reportagens de TV, que divulgavam com destaque imagens de corpos esquartejados, mutilados, carbonizados, cemitérios clandestinos e traficantes em poses de herói, disparando suas metralhadoras para o alto. (MELO, 200 p. 158)

En la verdad, lo que se ve claro es una especie de guerra civil no declarada que se desarrolló a partir de los años 70 y que ahora se encuentra en su ápice, proporcionando escalas aún más grandiosas de violencia para la sociedad brasileña de la actualidad, ofreciendo a todos un escenario de inseguridad y miedo.

\section{La construcción del sujeto joven de la favela}

Al tratar del sujeto joven en el escenario violento de las grandes ciudades brasileñas, es necesario decir que hay una ruptura en la formación de este sujeto, ya que el propio ambiente contribuye con estos cambios. Briceño-León afirma que los adolecentes se encuentran en una etapa de construcción de identidad y esto los hacen más vulnerables a las influencias del medio en que viven, agrega aún, que hay un cambio en estos adolecentes que ya no quieren ser más niños y sí, hombres (BRICEÑO, 2002 p. 42). Tales afirmaciones se pueden identificar en el personaje Reizinho, ya que desde temprana edad ya trabaja para la banda de drogas de la favela en que vive. Es necesario decir que al principio el personaje desarrollaba un servicio de vigilante para Miltão, el líder de la banda de drogas de la favela en que vivía, pero por un desliz suyo, éste se ve punido por Miltão y luego, fuera de la banda, debe ser agregado por pedido de su madre, Miltão no lo aceptó más en su organización.

Sin embargo, según Reizinho trabajar para Miltão, era algo que deseaba mucho y que lelo afirmaba como alguien, pues él veía un cierto status e incluso ventajas en aquellos que trabajaban para los traficantes y se sentía mal por no ser parte de esta organización. Al mismo tiempo, su hermana lo incentiva a trabajar para el tráfico, pues así, podría ser poderoso y respetado: "Você quer minha opinião? Melhor o tráfico, melhor o Miltão. Muito melhor. Isso mesmo, volte para o Miltão. Seja alguém. Ganhe uma metralhadora e mostre para eles" (MELO, 2003p. 49). 
Al hablar del poder que el arma representa, Briceño-León (2002 p. 42) señala que este objeto es referencial para la masculinidad y coraje que los jóvenes quieren mostrar. Sin embargo, no se comentan los problemas y riesgos que vienen junto con el arma en las manos de los jóvenes. Para Reizinho era necesario su participación en el tráfico para su afirmación como alguien, pues los trabajos para las bandas de drogas, le permitirían esto, a priori, su comportamiento lo lleva a las drogas, tornándose en poco tiempo adicto al crack.

No obstante, es importante señalar que la banda de drogas asume una postura que se relaciona con el poder representado por Miltão y que desarrolla un papel significativo para la vida de Reizinho, pues este ejerce un papel de salvación en su vida, aceptándolo en la banda de drogas, a pedido de su madre, al fin de que él se mantenga lejos de las drogas. Hace falta señalar que para Reizinho la banda de drogas representa un ideal de fuerza, de poder, reconocimiento y respeto de los demás para con aquellos que trabajaban con los traficantes. Para Muniz Sodré, el grupo proporciona un pasaje de la niñez a la vida adulta y esto seduce el adolescente.

En el caso de Reizinho se puede agregar aún que su familia presenta relaciones frágiles que se deshacen a todo instante, revelando lo que Muniz Sodré (2004, p. 85) denominó como "la muerte simbólica de los padres", pues éstos pierden su importancia que luego es transferida a las derivaciones grupales, en dicho caso, de las bandas de drogas.

Por fin, lo que se ve son jóvenes con relaciones problemáticas con sus familiares, sin sueños y al mismo tiempo víctimas y victimarios del escenario violento en que están insertados, pues la violencia ya forma parte de sus vidas cotidianas, en que el mejor camino es el de las bandas de drogas, pues les asegura poder, dinero y posición en la favela. De esta manera, se puede percibir que las experiencias significativas para este sujeto joven de las favelas son las que están involucradas con la vida arriesgada y casi siempre corta, pues normalmente jóvenes como él no tienen otra referencia.

\section{Las expectativas del joven de la actualidade}

Al abordar el tema de la violencia urbana en el universo juvenil de las favelas, es necesario decir que estas nuevas generaciones provenientes de las clases más pobres viven sin esperanzas y sueños para su futuro. Cuando hablamos de las expectativas del joven, estamos hablando de jóvenes pobres que conviven con un escenario violento y casi siempre no se les dan oportunidades para cambiar este cuadro. Esto puede ser identificado en el fragmento 
abajo, cuando la madre de Reizinho recuerda un diálogo que mantuvo con su hija, Carolaine, el cual presenta la falta de expectativas en la vida de la gente pobre:

Conhecia a vida, as coisas simplesmente não acontecem para nós, dizia. Foi até o portão, nunca vingavam, coisas boas, Carolaine não havia chegado do curso de computação. Coisas ruins aconteciam a toda hora. Meninas estupradas. Meninas grávidas. Meninas que se envolviam com os traficantes. (MELO, 2003 p. 27)

En el fragmento anteriormente citado, se puede percibir la ausencia de expectativas de una vida mejor, pues nos parece que ser honesto en este ambiente presentado en la novela estudiada es ser un sujeto desubicado y derrotado en el mundo actual, ya que la vida de estos personajes es un conjunto de dificultades y violencia frecuente. En relación a los jóvenes, ellos están en constante busca de la autoafirmación de su identidad y también como sujeto en este ambiente violento en que viven, a priori estos problemas los llevan a refugiarse en las drogas o en la delincuencia actuando como un desafío a la sociedad en que viven, aunque actúen produciendo una autodestrucción de sí mismo; esto se puede ver en el fragmento abajo, cuando el personaje Reizinho andaba sin rumbo por la calles cariocas, alimentándose solamente de su vicio:

Reizinho não pensaba em voltar para casa. Fazia quatro días que vivía nas ruas, andando, o dinheiro no bolso, largado nas praças e embaixo dos viadutos, fumando, indo à Praia, frequentando fliperamas, fumando, dormindo em qualquer lugar. Comprava pedras aos montes, nunca consumirá tanto quanto naqueles dias. (MELO, 2003 p. 95)

De esta manera, hay una deficiencia de las relaciones concretas que se reflejan el abandono de sí mismo, en la falta de sueños y esperanzas de una vida mejor, lo que hace que este joven busque refugio en las drogas con el instinto de sanar las privaciones y ausencias de su vida. En esta perspectiva, Muniz Sodré (2004, p.86) señala que la droga simula el vacío provocado por su existencia, actuando erróneamente con el objeto o el sujeto que no está ahí para este joven.

Al mismo tiempo, es necesario plantear el efecto que la falta de oportunidad le provoca, pues estas personas están insertadas en un medio donde las cosas no acontecen para ellos, los sueños son interrumpidos, los niños son convertidos en hombres, abandonando sus juegos infantiles por un arma, ya que luego son reclutados para trabajar en las bandas de drogas con el pensamiento de adquirir dinero y poder en la favela; Reizinho reflexiona sobre su condición social y piensa:

Bom nascer rico. Reizinho ganhava salário mínimo. Aquela merreca. Trabalhar oito horas por dia para receber "aquele coco mensal", como dizia para Fake. Quando era olheiro, trabalhava menos e recebia mais. Se fosse avião receberia mais ainda. Se fosse soldado de boca, mais e mais. Quanto ganha um gerente de boca? Muito mais. E se tomasse conta do morro, teria muito dinheiro. Se 
aumentasse seus pontos-de venda, se aumentasse o estoque de fuzis e metralhadoras, mais homens e granadas, cresceria, expadiria, seria rico, porra, praticamente rico. (MELO, 2003 p. 87).

De esta manera, se puede decir que los caminos propuestos por el trabajo y los estudios ya no ejercen influencia en estos jóvenes, pues se muestran frágiles e inoperantes, a priori, ellos no sanan rápidamente las carencias que son presentadas en su cotidianidad, haciendo de ellos, sujetos a margen de la sociedad capitalista y desigual en que están involucrados, ya que para ellos las referencias son de sujetos cercanos a su vida diaria y este es el universo que conocen, pues lo que está afuera, se presenta como enemigo o ajeno a su realidad.

En la novela Inferno, los moradores de la favela reconocían en los jefes de las bandas de drogas, una persona que les ayudaba, cuidaba a la favela y mantenía el orden dictando sus leyes e intercambiando favores, pues en este escenario la presencia del Estado casi no existe. Así, ellos son vistos como defensores de los más pobres por los moradores y como sujetos valientes y fuertes por los niños y adolecentes, a priori, esto seduce a los jóvenes a participar de estas bandas, pues ellos también quieren hacer parte del universo que el trafico produce que está vinculado a mucho dinero, muchas mujeres, gratitud por las personas de la favela y la posibilidad de comprar lo que desean. Esto se refiere en la fascinación que estos elementos favorecen en estos sujetos, pues se muestra como una posibilidad de cambio de vida y mejores condiciones para sí y para su familia.

Así, en la novela estudiada podemos ver que la desigualdad social del pasado se refleja asustadoramente en el ambiente de las favelas produciendo un universo de inconstancias y pérdidas para los que ahí viven, sobre todo para los jóvenes. Es importante señalar que las necesidades básicas, el deseo de consumo y las crecientes exigencias del mundo globalizado, hacen que los jóvenes estén fuera de las escuelas, pues ya no creen más en la educación y empiezan a trabajar desde temprana edad, abandonando los estudios para siempre y lanzándose deficientemente en el mercado laboral. No obstante, ellos no presentan un perfil para desarrollarse profesionalmente, porque no han accedido a la educación, restando solo el camino de la delincuencia, que se presenta como el camino más lucrativo y rentable para estos jóvenes.

De esta manera, la delincuencia se muestra como el camino más fácil para adquirir lo que le fue negado por su mala condición social, esto se refleja en la violencia creciente de las grandes ciudades brasileñas y que afecta asustadoramente a todos los que ahí viven, a priori, es necesario decir que la violencia no está relacionada con la pobreza, pues las áreas más pobres no son las más violentas, este hecho se refleja en los elementos de ordenes sociales que 
en Brasil se viene presentando desde los años 80 y que se extiende largamente hasta los días actuales, generando más exclusiones, más desigualdades y más violencia juvenil.

Finalmente, es importante señalar que estos jóvenes aparecen sin esperanzas y cambios para su vida futura, pues las expectativas y los sueños les son negados, configurando como sujetos excluidos del desarrollo nacional y así, se consideran incapaces de integrarse a esta sociedad capitalista y desigual en que viven.

\section{Conclusión}

El presente trabajo intentó mostrar desde la novela Inferno de Patricia Melo (2003) como se presenta el escenario violento de la ciudad de Rio de Janeiro y de las grandes metrópolis brasileñas. Así que fue planteado sobre cómo se dio los primeros señales de la violencia en las grandes ciudades y también como la creciente desigualdad social atinge a millones de brasileños que viven en las favelas, sin condiciones de acceder a una vida mejor.

En esta perspectiva fue dicho como se encuentra los jóvenes de bajo poder adquisitivo y que viven en las favelas, desde el personaje Reizinho que fue citado a lo largo del trabajo como ejemplo de cómo se encuentra los jóvenes que conviven como el trafico y la violencia común y corriente de su ambiente habitacional. Al mismo tiempo, se fue presentando cuáles son las expectativas de este sujeto joven, sus sueños y cómo les son sacados, pues lo que fue visto, a priori, es que son privados de esperanzas de días mejores, pues la situación en que viven no contribuyen para que reflexionen distintamente.

Así mismo, es necesario decir que en este trabajo se puede percibir que la desigualdad social y los incentivos al consumo exacerbado hacen que estas personas sean víctimas de las injusticias del mundo globalizado en que estamos insertos y que afecta enormemente a las generaciones brasileñas más pobres, generando la violencia y la delincuencia juvenil como respuesta a las privaciones de que son víctimas.

Finalmente, es necesario agregar aún que este trabajo es importante para los estudios sobre la violencia y delincuencia juvenil en las metrópolis brasileñas; sobre todo, se intenta llamar la atención de cómo este factor se están tornando aún peor y de cuáles son los problemas que están presentes en esta juventud de un país dividido entre pobres y ricos que está viviendo una guerra civil no declarada, donde los más pobres son víctimas del sistema opresor y también de las bandas de drogas, llevando a la reflexión de cómo se encuentra el escenario brasileño de la actualidad que se presenta en proporciones grandiosas con el pasar del tiempo. 


\section{Referências}

MELO. Patricia. Inferno. São Paulo: Companhia das Letras, 2003

MUNIZ, Sodré. Sociedade, mídia e violência. Porto Alegre: Sulinas, 2004.

CANCLINI, Néstor García. Culturas híbridas: estrategia para entrar y salir de la modernidad. Buenos Aires: Paidós, 2001.

BRICEÑO-LEÓN, Roberto. La nueva violencia urbana de América Latina.

Disponible en: http://www.scielo.br/pdf/soc/n8/n8a03.pdf.

Acceso en: 20/04/2008

CANDELARIO, Sheila. Violencia, globalización y literatura: O el dilema del Eterno Retorno en El Salvador.

Disponible en: http://www.denison.edu/collaborations/istmo/n08/articulos/violencia.html. Acceso en: 20/04/2008

JIMÉNEZ, María de la Villa Moral. Jóvenes, violencia y tribalidad urbana como forma emergente de identidad difusa.

Disponible en: http://www.psico.uniovi.es/REIPS/v2n1/art2.html.

Acceso en: 20/04/2008 